\title{
Incidência e viabilidade de sementes crioulas de milho naturalmente infestadas com fungos em pré e pós-armazenamento
}

\author{
Incidence and viability of creole seeds of corn naturally infested with fungi in pre-and \\ post-storage
}

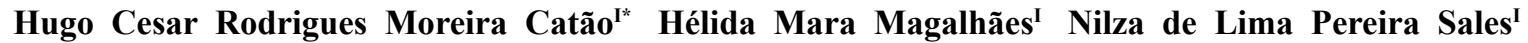 \\ Delacyr da Silva Brandão Junior ${ }^{I}$ Fernando da Silva Rocha ${ }^{I}$
}

\section{RESUMO}

Objetivou-se com este trabalho avaliar a qualidade sanitária e fisiológica de quatorze variedades de sementes de milho crioulas em pré e pós-armazenamento em embalagens de polietileno tereftalato (PET). Houve efeito das variedades e das épocas de avaliações sobre a incidência de fungos e germinação. Dentre a micobiota observada, Fusarium moniliforme (88\%), Penicillium spp. (6,9\%) e Aspergillus spp. (2,1\%) tiveram a maior porcentagem de incidência. Após o armazenamento, houve decréscimo de F. moniliforme (69\%) e aumento de Penicillium spp. (35\%) e Aspergillus spp. (22\%). A incidencia desses fungos não comprometeu a qualidade fisiológica das sementes, que apresentaram elevadas porcentagens de vigor e germinação.

Palavras-chave: Zea mays, teste de sanidade, fungos patogênicos, germinação, vigor.

\section{ABSTRACT}

The objective of this study was to evaluate the sanitary and physiological quality of fourteen varieties of creole corn seeds in pre-and post-storage in packaging of polyethylene terephthalate (PET). Among the mycobiota observed Fusarium moniliforme (88\%), Penicillium spp. (6,9\%) and Aspergillus spp. (2,1\%) had the highest incidence. After storage there was a slight decrease in the percentage of $\boldsymbol{F}$. moniliforme (69\%) and a increase of Penicillium spp. (35\%) and Aspergillus spp. (22\%). The incidence of these fungi did not compromise the physiological quality of seeds that showed high percentages of vigor and germination.

Key words: Zea mays, sanity test, pathogenic fungi, germination, vigor.

\section{INTRODUÇÃO}

O milho é um dos cereais mais cultivados em todo o mundo, sendo importante na alimentação humana e animal. A partir dos anos 50, ocorreu uma série de transformações na agricultura, entre as quais as alterações genéticas foram, talvez, as que mais afetaram a vida dos agricultores (MENEGUETTI et al., 2002). Ao longo dos anos, as variedades crioulas foram substituídas por híbridos e materiais melhorados geneticamente.

As variedades crioulas tendem a tolerar melhor as variações ambientais e são mais resistentes ao ataque de patógenos por serem mais adaptadas às condições locais. As populações "crioulas" são materiais importantes para o melhoramento genético, pelo elevado potencial de adaptação que apresentam em condições ambientais específicas (PATERNIANI et al., 2000) e, por constituírem fonte de variabilidade genética, podem ser exploradas na busca por genes tolerantes e/ou resistentes aos fatores bióticos e abióticos (ARAÚJO \& NASS, 2002). Para ANTONELLO et al. (2009), as variedades crioulas são importantes para os pequenos agricultores, que as utilizam amplamente em sua base alimentar, na dieta de suas famílias e animais, manutenção da história (tradições), cultura e costumes das comunidades e como fonte de renda.

A utilização de sementes de qualidade comprovada constitui-se em fator preponderante para o estabelecimento das lavouras, possibilitando maiores produções. Asemente éum fator determinante do sucesso ou fracasso da produção, uma vez que contém todas as potencialidades produtivas da

Instituto de Ciências Agrárias, Universidade Federal de Minas Gerais (UFMG), 39404-006, Montes Claros, MG, Brasil. E-mail: hugocatao@yahoo.com.br. *Autor para correspondência. 
planta e é praticamente o único insumo ao alcance do pequeno agricultor (COSTA \& CAMPOS, 1997). No Brasil, entrou em vigor a lei de sementes n.10.711/03, em que as sementes crioulas passam a ser oficialmente reconhecidas. Entretanto, a lei não regulamenta o controle de qualidade do material crioulo, ao contrário das cultivares comerciais existentes no mercado (CAMPOS et al., 2006).

Muitos patógenos podem comprometer a qualidade das sementes e estes podem ser divididos em dois grupos: os de campo e os de armazenamento (MILLER, 1995; TANAKA et al., 2001). Dentre os principais fungos de campo patogênicos do milho, destacam-se o Fusarium moniliforme lato sensu (Sheld.), Stenocarpella maydis (Berk), Cephalosporium sp. (PINTO, 2000) e os fungos considerados de armazenamento pertencem ao gênero Penicillium e Aspergillus (MILLER, 1995).

No norte de Minas Gerais, a cultura do milho é, em alguns casos, a principal fonte de renda dos agricultores familiares. Porém, não há informações sanitárias e fisiológicas de como produzir sementes crioulas de boa qualidade respeitando as normas de controle, baseando-se em ações preventivas que garantam a manutenção dessa qualidade ao longo do processo de produção. Dessa forma, objetivouse, neste trabalho, avaliar a qualidade sanitária e fisiológica de sementes de variedades crioulas de milho em pré e pós-armazenamento em embalagens de polietileno tereftalato (PET).

\section{MATERIAL E MÉTODOS}

Foram utilizadas sementes de 14 variedades de milho crioulas, provenientes do município de Porteirinha-MG e colhidas na safra 2006/2007. Durante o período de produção das sementes, foram coletados os dados médios mensais de temperatura $\left({ }^{\circ} \mathrm{C}\right)$ e umidade relativa do ar $(\%)$, além dos dados totais de precipitação $(\mathrm{mm})$. No laboratório de Fitopatologia da Universidade Federal de Minas Gerais do Instituto de Ciências Agrárias da (ICA/UFMG), realizaram-se os testes de qualidade sanitária logo após a colheita, em maio de 2007, e após o armazenamento das sementes, em dezembro de 2007. Amostras de $1 \mathrm{~kg}$ de sementes foram préarmazenadas em sacos de papel kraft, assim que foram colhidas, e posteriormente conduzidas ao laboratório para procederem às análises de sua micobiota. $\mathrm{O}$ restante das sementes foi armazenado em câmara seca $\left(22^{\circ} \mathrm{C}\right.$ e $35-45 \%$ UR), pós-armazenamento, em garrafas PET (polietileno tereftalato) por um período de sete meses.
Para verificar a micobiota das sementes de milho, utilizou-se o teste de sanidade por meio do método do papel de filtro com congelamento (MACHADO, 2000). As sementes foram desinfetadas em hipoclorito de sódio $2 \%$ por três minutos e, em seguida, lavadas três vezes em água destilada esterilizada, sendo, posteriormente, secas em câmara de fluxo laminar. Após, as sementes foram acondicionadas em caixas gerbox $(11 \times 11 \times 3 \mathrm{~cm})$ esterilizadas (álcool 70\%), contendo duas folhas de papel germinativo umedecidos com meio ágar-água $(10 \%)$. Inicialmente, as sementes foram mantidas em câmara incubadora BOD por um período inicial de 24 horas sob temperatura $25 \pm 2^{\circ} \mathrm{C}$ e, em seguida, em congelador $\left(-20^{\circ} \mathrm{C}\right)$ por 24 horas, e finalmente retornadas à incubadora a $25 \pm 2^{\circ} \mathrm{C}$ durante sete dias, sob fotoperíodo de 12 horas de luz fluorescente branca. Foram utilizadas 20 repetições com 20 sementes por parcela, totalizando 400 sementes, para a realização do teste de sanidade (BRASIL, 2009a). Após a incubação, as sementes foram examinadas sob microscópio estereoscópico e, quando necessário, foram feitas lâminas com as estruturas dos fungos para a visualização e identificação em microscópio composto. A identificação de $\boldsymbol{F}$. moniliforme foi realizada seguindo a chave de classificação de VENTURA (2000). Aspergillus e Penicillium foram identificados utilizando a chave de identificação descrita por KLICH \& PITT (2002).

$\mathrm{O}$ experimento foi montado em delineamento inteiramente casualisado (DIC) e os fungos de maior incidência foram submetidos à análise fatorial em duas épocas de avaliação das sementes (esquema fatorial $2 \times 3$; avaliação em pré e pós-armazenamento e três espécies de fungos).

No Laboratório de Análise de Sementes (LAS) do ICA/UFMG, avaliou-se a qualidade fisiológica das 14 variedades de milho crioulo. Para tanto, as sementes foram submetidas ao teste padrão de germinação prescrito pelas Regras para Análises de Sementes (BRASIL, 2009), em germinador tipo Mangelsdorf a temperatura de $25^{\circ} \mathrm{C}$ constante. As sementes foram consideradas germinadas pela ocorrência da protrusão da radícula em $5 \mathrm{~mm}$. $\mathrm{O}$ experimento foi conduzido em delineamento inteiramente casualizado (DIC) arranjado em esquema fatorial $14 \times 2$ (sementes de quatorze variedades de milho crioulo e duas épocas de avaliação das sementes em pré e pós-armazenamento) com quatro repetições e 25 sementes por parcela.

Os dados foram submetidos à análise de variância e as médias comparadas pelo teste de Scott-Knott a $(\mathrm{P}<0,05)$ de probabilidade. Também

Ciência Rural, v.43, n.5, mai, 2013. 
foi realizada análise de correlação linear de Pearson entre a incidência dos fungos, germinação e vigor. A significância dos coeficientes de correlação foi verificada pelo teste $\mathrm{F}$ a $(\mathrm{P}<0,05)$ de probabilidade. Os dados de percentagem foram transformados para $y=\operatorname{arcsen}(\sqrt{x / 100})$.

\section{RESULTADOS E DISCUSSÃO}

A maior incidência de fungos nas sementes de milho crioulo produzidas no município de Porteirinha-MG foi de Fusarium moniliforme, seguidos por Penicillium spp. e Aspergillus spp. Resultado similar foi relatado por JORGE et al. (2005), em que variedades de milho apresentaram incidência de $\boldsymbol{F}$. moniliforme acima de $62 \%$ nas sementes. A maior incidência de Penicillium spp. e Aspergillus spp. foi verificada na variedade Cateto Anã (16,5\%) e Cateto Crioulo (8,25\%). Os demais fungos encontrados foram Drechslera sp. em porcentagens abaixo de 1,75\%, Trichoderma sp. a 19,5\% e Exerohilum turcicum a 0,25\% (Tabela 1). Exerohilum turcicum é um dos principais patógenos da cultura do milho, parasitando a parte aérea das plantas e também infectando as sementes (BRASIL, 2009a).

As espécies encontradas no presente trabalho podem ser divididas em fungos que são transmitidos às plantas e plântulas via sementes, como Fusarium moniliforme e fungos de armazenamento, em que se enquadram espécies como Penicillium spp. e Aspergillus spp. (WAGNER \& MITSCHUNAS,
2008; SOLORZANO \& MALVICK, 2011). Esses microrganismos são os mais frequentemente encontrados em sementes de milho (JORGE et al., 2005).

Houve diferença estatística entre as variedades e as épocas de avaliação para os três principais fungos analisados. No pré-armazenamento, as variedades Branco da Barra, Coruja, Tupiniquim Doce e Catingueiro tiveram maiores porcentagens de sementes infectadas com $\boldsymbol{F}$. moniliforme, quando comparadas as outras variedades (Tabela 2). De maneira geral, após o armazenamento das sementes, houve ligeiro decréscimo desse fungo. Resultados semelhantes foram observados por MACEDO et al. (2002) em dois lotes de sementes de arroz, armazenados por doze meses em plástico trançado, que apresentou decréscimo pouco acentuado de $\boldsymbol{F}$. moniliforme. Quanto aos fungos de armazenamento, Penicillium spp. e Aspergillus spp., em geral, houve aumento na incidência após os sete meses para todas as variedades, entretanto, diferenças estatísticas para o efeito da época de avaliação não foram observadas em relação a Penicillium spp. para as variedades Santo e Coruja, bem como Aspergillus spp. para as variedades Santo, Tupiniquim Doce e Amarelinho (Tabela 2). Os fungos de armazenamento, por sua vez, estão presentes nas sementes recém-colhidas, geralmente em porcentagens muito baixas e são capazes de sobreviver em ambiente com baixa umidade, proliferando em sucessão aos fungos de campo, causando a deterioração das sementes, além de produzirem toxinas que causam intoxicações em

Tabela 1 - Incidência (\%) de fungos associados às sementes das variedades de milho crioulo.

\begin{tabular}{|c|c|c|c|c|c|c|}
\hline Variedades & FUS & PEN & ASP & DRE & TRIC & $\mathrm{EXE}^{*}$ \\
\hline Amarelão & 91,25 & 0,25 & 0,25 & 0,00 & 0,00 & 0,00 \\
\hline Santo & 83,25 & 11,50 & 5,75 & 0,00 & 0,00 & 0,00 \\
\hline Asteca & 76,00 & 4,75 & 1,00 & 0,00 & 0,00 & 0,00 \\
\hline Branco da barra & 98,50 & 0,75 & 2,00 & 0,00 & 0,00 & 0,00 \\
\hline Coruja & 88,25 & 6,25 & 0,00 & 0,00 & 19,5 & 0,00 \\
\hline Tupiniquim doce & 99,00 & 2,75 & 2,50 & 1,25 & 0,00 & 0,25 \\
\hline Cateto anão & 99,50 & 16,50 & 0,00 & 0,25 & 0,00 & 0,00 \\
\hline Catingueiro & 99,75 & 4,75 & 3,25 & 0,75 & 0,00 & 0,00 \\
\hline Cateto crioulo & 91,25 & 6,25 & 8,25 & 0,00 & 0,00 & 0,00 \\
\hline Caiçara & 84,25 & 1,50 & 1,50 & 1,25 & 0,00 & 0,00 \\
\hline Amarelinho & 79,00 & 7,25 & 0,00 & 0,00 & 0,00 & 0,00 \\
\hline Tio João & 90,75 & 12,75 & 0,50 & 1,75 & 0,00 & 0,00 \\
\hline Mineiro amarelo & 79,50 & 4,50 & 2,50 & 1,50 & 0,00 & 0,00 \\
\hline Flor do campo & 62,75 & 2,00 & 2,00 & 0,00 & 0,00 & 0,00 \\
\hline
\end{tabular}

* FUS (Fusarium moniliforme), PEN (Penicillium spp.), ASP (Aspergillus spp.), DRE (Drechslera sp.), TRIC (Trichoderma sp.), EXE (Exerohilum turcicum). 
Tabela 2 - Incidência (\%) de $\boldsymbol{F}$. moniliforme, Penicillium spp. e Aspergillus spp. nas sementes de milho crioulo pré (PRE) e pósarmazenadas (POS).

\begin{tabular}{|c|c|c|c|c|c|c|}
\hline \multirow{2}{*}{ Variedades } & \multicolumn{2}{|c|}{ - F. moniliforme------- } & \multicolumn{2}{|c|}{---Penicillium spp-------- } & $-A \mathrm{spe}$ & \multirow[b]{2}{*}{ POS } \\
\hline & PRE & POS & PRE & POS & PRE & \\
\hline Amarelão & $90,81 \mathrm{Ab}$ & $90,75 \mathrm{Aa}$ & $0,26 \mathrm{Bb}$ & $14,25 \mathrm{Da}$ & $0,26 \mathrm{Cb}$ & $12,75 \mathrm{Da}$ \\
\hline Santo & $83,06 \mathrm{Aa}$ & $79,56 \mathrm{Ba}$ & $11,50 \mathrm{Aa}$ & $19,00 \mathrm{Da}$ & $5,75 \mathrm{Ba}$ & $3,75 \mathrm{Ea}$ \\
\hline Asteca & $76,00 \mathrm{Aa}$ & $55,25 \mathrm{Cb}$ & $11,25 \mathrm{Ab}$ & $83,25 \mathrm{Aa}$ & $1,01 \mathrm{Cb}$ & $72,43 \mathrm{Aa}$ \\
\hline Branco da barra & $97,43 \mathrm{Cb}$ & $85,56 \mathrm{Ba}$ & $0,76 \mathrm{Bb}$ & $24,50 \mathrm{Ca}$ & $1,76 \mathrm{Cb}$ & $13,75 \mathrm{Da}$ \\
\hline Coruja & $97,18 \mathrm{Cb}$ & $62,31 \mathrm{Ca}$ & $6,75 \mathrm{Aa}$ & $12,00 \mathrm{Da}$ & $0,01 \mathrm{Cb}$ & $4,75 \mathrm{Ea}$ \\
\hline Tupiniquim doce & $97,93 \mathrm{Cb}$ & $96,93 \mathrm{Aa}$ & $2,76 \mathrm{Bb}$ & $30,50 \mathrm{Ca}$ & $2,50 \mathrm{Ba}$ & $6,50 \mathrm{Ea}$ \\
\hline Cateto anão & $94,75 \mathrm{Bb}$ & $79,00 \mathrm{Ba}$ & $16,50 \mathrm{Ab}$ & $45,68 \mathrm{Ba}$ & $0,26 \mathrm{Cb}$ & $38,25 \mathrm{Ca}$ \\
\hline Catingueiro & $98,50 \mathrm{Cb}$ & $93,62 \mathrm{Aa}$ & $10,75 \mathrm{Bb}$ & $47,75 \mathrm{Ba}$ & $3,25 \mathrm{Bb}$ & $51,25 \mathrm{Ba}$ \\
\hline Cateto crioulo & $91,00 \mathrm{Aa}$ & $33,12 \mathrm{Db}$ & $6,25 \mathrm{Ab}$ & $55,50 \mathrm{Ba}$ & $8,25 \mathrm{Aa}$ & $12,50 \mathrm{~Eb}$ \\
\hline Caiçara & $93,00 \mathrm{Ab}$ & $90,50 \mathrm{Aa}$ & $2,75 \mathrm{Bb}$ & $38,18 \mathrm{Ca}$ & $1,51 \mathrm{Cb}$ & $6,00 \mathrm{Ea}$ \\
\hline Amarelinho & $78,87 \mathrm{Aa}$ & $26,75 \mathrm{Db}$ & $7,25 \mathrm{Ab}$ & $32,12 \mathrm{Ca}$ & $0,01 \mathrm{Ca}$ & $3,25 \mathrm{Ea}$ \\
\hline Tio João & $90,37 \mathrm{Aa}$ & $68,93 \mathrm{Ba}$ & $12,75 \mathrm{Aa}$ & $21,25 \mathrm{Ca}$ & $0,51 \mathrm{Cb}$ & $24,25 \mathrm{Da}$ \\
\hline Mineiro amarelo & $81,31 \mathrm{Ab}$ & $81,56 \mathrm{Aa}$ & $4,50 \mathrm{Bb}$ & $18,75 \mathrm{Da}$ & $2,50 \mathrm{Bb}$ & $40,25 \mathrm{Ca}$ \\
\hline Flor do campo & $62,75 \mathrm{Aa}$ & $23,75 \mathrm{Db}$ & $2,00 \mathrm{Bb}$ & $50,43 \mathrm{Ba}$ & $2,01 \mathrm{Cb}$ & $23,25 \mathrm{Da}$ \\
\hline $\mathrm{CV}(\%)$ & & 38,86 & & 66,28 & & 74,07 \\
\hline
\end{tabular}

* Médias não seguidas pela mesma letra, minúscula nas colunas, e maiúscula nas linhas para a época de avaliação diferem entre si pelo teste Scott-Knott e F, respectivamente, a $5 \%$ de probabilidade.

humanos e animais (MILLER, 1995; CARVALHO \& NAKAGAWA, 2000). O tempo de sobrevivência desses fungos nas sementes está diretamente relacionado com as condições de ambiente do armazém, teor de água, inóculo inicial, tipo de espécie ou variedade e estado físico (WICKLOW et al., 1998).

A alta incidência de $\boldsymbol{F}$. moniliforme no préarmazenamento pode estar associada às condições ambientais durante a produção das espigas. Os fungos de campo necessitam de umidade relativa elevada, acima de $80 \%$ para completarem seu ciclo biológico, enquanto os fungos considerados de armazenamento demandam de menor quantidade de água para proliferarem durante o período de pós-colheita (NEVES, 2007). Os dados meteorológicos médios mensais registrados nos meses de janeiro e fevereiro apresentaram temperatura média de 29 e $26,4^{\circ} \mathrm{C}$, altos índices de umidade relativa do ar (82 e 85,5\%) em decorrência do período chuvoso com precipitações de 129,8 e $272,9 \mathrm{~mm}$, respectivamente (INMET, 2007), período característico da região do norte de Minas Gerais (de acordo com Köeppen, o clima é denominado Aw - clima tropical de savana com inverno seco e verão chuvoso, também classificado como semiárido). Nesses meses, as plantas estavam na fase de pendoamento, em seguida, de enchimento de grãos e as chuvas, aliadas à alta umidade podem ter contribuído para o estabelecimento $\boldsymbol{F}$. moniliforme nas sementes. SARTORI et al. (2004) verificaram que este fungo pode ser transmitido até 45 dias após a semeadura para diferentes órgãos da planta, a partir de sementes de milho naturalmente infectadas. A incidência de $\boldsymbol{F}$. moniliforme reduziu com o período de armazenamento em condições convencionais, fato também descrito por WICKLOW et al. (1998); OLIVEIRA et al. (1997) e TANAKA et al. (2001). Entretanto, apesar da redução de $\boldsymbol{F}$. moniliforme, após sete meses de armazenamento, a incidência manteve-se alta para grande parte das variedades, provavelmente devido às condições inerentes ao armazenamento, como teores de gases e umidade no interior das garrafas PET. WEINBERG et al. (2008) verificaram que sementes de milho armazenadas em recipientes fechados com 20 a $22 \%$ de umidade apresentaram menores taxas de germinação e maior crescimento de leveduras e bactérias, além do aumento de dióxido de carbono em relação ao oxigênio, levando à produção de etanol e ácido acético no recipiente. Além disso, características do lote de sementes, especialmente o estado físico, teor de água e inóculo inicial, podem ter contribuído para a manutenção desse fungo. É provável que essas hipóteses se apliquem no presente trabalho. Contudo, seriam necessários futuros desdobramentos para atestar tal probabilidade. 
O fungo $\boldsymbol{F}$. moniliforme é um dos patógenos que causa podridão do colmo e da espiga de milho, acarretando queda na produtividade da cultura (SARTORI et al., 2004). Sabe-se ainda que esse fungo pode, saprofiticamente, manter-se nos tegumentos remanescentes das sementes e também sobreviver em restos culturais. Esse patógeno pode ser transportado pelas sementes e as consequências são: a introdução em áreas isentas, o aumento do inóculo na área e a redução da qualidade fisiológica das sementes (MACHADO, 2000). Existem trabalhos controversos quando se trata do efeito de patógenos sobre a qualidade fisiológica de sementes de milho. PINTO (2000) constatou que $\boldsymbol{F}$. moniliforme, Penicillium sp. e Aspergillus spp. não afetaram a germinação de sementes de milho, enquanto que LUCCA FILHO (1984) afirmou que esses mesmos patógenos e Diplodia maydis podem contribuir para a redução do poder germinativo de sementes de milho.

No presente trabalho, os patógenos mencionados não comprometeram a qualidade fisiológica das sementes de milho. Quando se realizou análise de correlação linear de Pearson entre os fungos detectados, a germinação e vigor das sementes (Tabela 3), pôde-se observar que não houve relação entre as variáveis analisadas, corroborando os resultados encontrados por PINTO (2000). Isso indica que os fungos encontrados são infestantes e não infectavam as sementes. Considera-se infestação a associação do patógeno a um tecido sem atividade enzimática, superficial ou externo e uma infecção, quando ocorre em um tecido interno, com atividade vital (MACHADO, 2000). No solo, esses fungos podem atacar as sementes de milho, principalmente, quando a semeadura é realizada em condições não ideais, isto é, em solo frio e úmido, onde há impedimento da germinação ou redução da velocidade de emergência, propiciando uma maior exposição ao ataque dos fungos (PINTO,
2000). Dessa forma, recomenda-se o tratamento das sementes analisadas visando principalmente à proteção contra fungos de solo.

O nível da qualidade fisiológica das sementes (Tabela 4) pode ser avaliado por meio de parâmetros fundamentais: viabilidade e vigor (POPINIGIS, 1985). Das variedades analisadas, 13 alcançaram percentagens de germinação superiores a $90 \%$ no período anterior ao armazenamento. Treze variedades não diferiram estatisticamente, tendo as variedades Santo e Amarelão apresentado menor germinação. Das variedades analisadas, apenas a variedade Amarelão apresentou-se inferior ao padrão exigido (85\%), inviabilizando sua comercialização. Provavelmente, esse resultado pode estar relacionado a problemas específicos do lote amostrado; contudo, após o armazenamento, todas as variedades atenderam às exigências da legislação.

$\mathrm{O}$ armazenamento em garrafas PET, de uma forma geral, apresentou-se eficiente na manutenção da qualidade fisiológica e, em menor proporção, na qualidade sanitária das sementes. Resultados similares foram descritos por ANTONELLO et al. (2009), que verificaram os efeitos positivos de embalagens plásticas na manutenção da qualidade das sementes de milho crioulo. SILVA et al. (2005) afirmaram que as embalagens plásticas propiciaram um baixo nível de oxigênio em seu interior, limitando a presença de insetos-praga e fungos.

\section{CONCLUSÃO}

As sementes crioulas de milho apresentaram micobiota diversificada, tendo como os principais representantes os fungos Fusarium moniliforme, Penicillium spp. e Aspergillus spp. A incidência de $\boldsymbol{F}$. moniliforme foi maior em pré-armazenamento, enquanto Penicillium spp. e Aspergillus spp. em

Tabela 3 - Coeficiente linear de Pearson (r) entre médias de incidência de $\boldsymbol{F}$. moniliforme, Penicillium spp. e Aspergillus spp. e porcentagem de germinação e vigor de sementes de milho crioulo em pré e pós-armazenamento.

\begin{tabular}{|c|c|c|c|c|}
\hline \multirow{2}{*}{ Fungos } & \multirow[b]{2}{*}{ Pré-armazenamento } & \multirow[b]{2}{*}{ Pós- armazenamento } & \multirow[b]{2}{*}{ Pré-armazenamento } & \multirow[b]{2}{*}{ Pós- armazenamento } \\
\hline & & & & \\
\hline & $\mathrm{R}$ & $\mathrm{R}$ & $\mathrm{R}$ & $\mathrm{R}$ \\
\hline F. moniliforme & $-0.0197^{\mathrm{ns}}$ & $-0.0632^{\mathrm{ns}}$ & $-0.0507^{\text {ns }}$ & $-0.0089^{\mathrm{ns}}$ \\
\hline Penicillium spp. & $0.0883^{\mathrm{ns}}$ & $-0.1512^{\mathrm{ns}}$ & $0.2451^{\mathrm{ns}}$ & $-0.1789^{\mathrm{ns}}$ \\
\hline Aspergillus spp. & $-0.0790^{\mathrm{ns}}$ & $0.0663^{\mathrm{ns}}$ & $0.0980^{\mathrm{ns}}$ & $0.0732^{\mathrm{ns}}$ \\
\hline
\end{tabular}

* Não significativo (ns) em nível de 5\% de probabilidade pelo teste F. 
Tabela 4 - Porcentagem de germinação e vigor (\%) das sementes de milho crioulo em pré e pós-armazenamento, produzidas em Porteirinha, Minas Gerais (Fonte: adaptado de CATÃO et al., 2010).

\begin{tabular}{|c|c|c|c|c|}
\hline \multirow{2}{*}{ Variedades } & \multicolumn{2}{|c|}{------------------------Vigor (\%)------------------------- } & \multicolumn{2}{|c|}{ 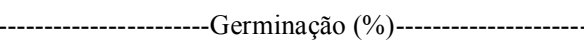 } \\
\hline & Pré-armazenamento & Pós- armazenamento & Pré-armazenamento & Pós- armazenamento \\
\hline Amarelão & $79 b B$ & $96 \mathrm{aA}$ & $81 \mathrm{cB}$ & $97 \mathrm{aA}$ \\
\hline Santo & $81 \mathrm{bB}$ & $95 \mathrm{bA}$ & $91 \mathrm{bA}$ & $96 \mathrm{aA}$ \\
\hline Asteca & $96 \mathrm{aA}$ & $95 \mathrm{bA}$ & $98 \mathrm{aA}$ & $95 \mathrm{bA}$ \\
\hline Branco da barra & $99 \mathrm{aA}$ & $92 \mathrm{bB}$ & $100 \mathrm{aA}$ & $92 \mathrm{bB}$ \\
\hline Coruja & $95 \mathrm{aA}$ & $99 \mathrm{aA}$ & $98 \mathrm{aA}$ & $99 \mathrm{aA}$ \\
\hline Tupiniquim doce & $95 \mathrm{aA}$ & $96 \mathrm{aA}$ & $97 \mathrm{aA}$ & $96 \mathrm{bA}$ \\
\hline Cateto anão & $97 \mathrm{aA}$ & $92 \mathrm{bA}$ & $100 \mathrm{aA}$ & $94 \mathrm{bA}$ \\
\hline Catingueiro & $97 \mathrm{aA}$ & $100 \mathrm{aA}$ & $98 \mathrm{aA}$ & $100 \mathrm{aA}$ \\
\hline Cateto crioulo & $99 \mathrm{aA}$ & $90 \mathrm{bB}$ & $100 \mathrm{aA}$ & $90 \mathrm{bB}$ \\
\hline Caiçara & $97 \mathrm{aA}$ & $93 \mathrm{bA}$ & $97 \mathrm{aA}$ & $93 \mathrm{bA}$ \\
\hline Amarelinho & $99 \mathrm{aA}$ & $98 \mathrm{aA}$ & $98 \mathrm{aA}$ & $98 \mathrm{aA}$ \\
\hline Tio João & $97 \mathrm{aA}$ & $94 \mathrm{bA}$ & $97 \mathrm{aA}$ & $94 \mathrm{bA}$ \\
\hline Mineiro amarelo & $90 \mathrm{aA}$ & $95 \mathrm{bA}$ & $97 \mathrm{aA}$ & $95 \mathrm{bA}$ \\
\hline Flor do campo & $100 \mathrm{aA}$ & $98 \mathrm{aA}$ & $100 \mathrm{aA}$ & $98 \mathrm{aA}$ \\
\hline $\mathrm{CV}(\%)$ & & 6,94 & & 5,71 \\
\hline
\end{tabular}

*Médias não seguidas pela mesma letra minúscula nas colunas e maiúscula nas linhas para a época de avaliação diferem entre si pelo teste Scott-Knott a $5 \%$ de probabilidade.

pós-armazenamento. Os referidos fungos não comprometeram a qualidade fisiológica das sementes que apresentaram altos níveis de germinação e vigor, exceto para a cultivar 'Amarelão'. Recomenda-se o tratamento fungicida das sementes antes do plantio.

\section{REFERÊNCIAS}

ANTONELLO, L.M. et al. Influência do tipo de embalagem na qualidade fisiológica de sementes de milho crioulo. Revista Brasileira de Sementes, v.31, n.4, p.75-86, 2009. Disponível em: $\quad<\mathrm{http}: / / \mathrm{www}$. scielo.br/scielo.php?pid=S010131222009000400009\&script=sci_arttext $>$. Acesso em: 18 jun. 2010. doi: $10.1590 / \mathrm{S} 0101-31222009000400009$.

ARAÚJO, P.M.; NASS, L.L. Caracterização e avaliação de populações de milho crioulo. Scientia Agrícola, v.59, n.3, p.589-593, 2002. Disponível em: <http://www.scielo.br/scielo. php? script $=$ sci_arttext\&pid $=S 0103-90162002000300027>$. Acesso em: 15 ago. 2011. doi: 10.1590/S010390162002000300027.

BRASIL. Ministério da Agricultura e Reforma Agrária. Regras para análises de sementes. Brasília: SNDA/DNDV/CLAV, 2009. 398p.

BRASIL. Ministério da Agricultura, Pecuária e Abastecimento. Manual de análise sanitária de sementes. Brasília-DF, 2009a. 202p.
CAMPOS, S.R.F. et al. Aspectos legais da produção e da comercialização de sementes. Informe Agropecuário, v.27, n.232, p.52-58, 2006.

CARVALHO, N.M.; NAKAGAWA, J. Sementes: ciência, tecnologia e produção. Jaboticabal, Funep, 2000. 588p.

CATÃO, H.C.R.M. et al. Qualidade física, fisiológica e sanitária de semente de milho crioulo produzidas no norte de Minas Gerais. Ciência Rural, v.40, n.10, p.2060-2066, 2010. Disponível em: <http://www.scielo.br/scielo.php?pid=S0103$84782010001000002 \&$ script $=$ sci_arttext $>$. Acesso em: 20 maio, 2011. doi: $10.1590 / \mathrm{S} 0103-84782010001000002$.

COSTA, J.G.; CAMPOS, I.S. Recomendações básicas para a produção de sementes de milho no nível da pequena propriedade rural. Acre: Embrapa - Centro de Pesquisa Agroflorestal do Acre, 1997. (Instrução Técnica, n.4, p.1-3).

INMET (INSTITUTO NACIONAL DE METEOROLOGIA). $5^{\circ}$ Distrito de Meteorologia (2007). Disponível em: <www.inmet. gov.br>. Acesso em: 06 abr. 2007.

JORGE, M.H.A. et al. Qualidade fisiológica e sanitária de sementes de milho colhidas e secas em espigas. Bragantia, v.64, n.4, p.679-686, 2005. Disponível em: <http://www.scielo.br/ scielo.php?script=sci_arttext\&pid=S0006-87052005000400018>. Acesso em: 15 ago. 2011. doi: 10.1590/S000687052005000400018 . 
KLICH, M.A.; PITT, J.I. A laboratory guide to the common Aspergillus species and their teleomorphs. Australia: CSIRO Division of Food Processing, 2002. 116p.

Legislação brasileira sobre sementes e mudas: Lei $n$ 10.711 , de 5 de agosto de 2003 e Decreto n. 5.153, de 23 de julho de 2004. Brasília, 2004. 121p.

LUCCA FILHO, O.A. Diagnóstico da patologia de sementes de milho no Estado do Rio Grande do Sul. In: SIMPÓSIO BRASILEIRO DE PATOLOGIA DE SEMENTES, Situação e perspectivas da patologia de sementes no Brasil, 1984, Piracicaba, SP. Anais... Piracicaba: CENA/USP/CNEN, Brasília: ABRATES, 1984. p.102-104.

MACEDO, E.C. et al. Influência da embalagem e do armazenamento na qualidade sanitária de sementes de arroz. Revista Brasileira de Sementes, v.24, n.1, p.42-50, 2002. Disponível em: <http://www. scielo.br/scielo.php?pid=S0101-31222002000100007\&script $=$ sci arttext>. http://dx.doi.org/10.1590/S0101-1222002000100007. Acesso em: 15 jun. 2011 .

MACHADO, J.C. Tratamento de sementes no controle de doenças. Lavras: LAPS/UFLA/FAEPE, 2000. 138p.

MENEGUETTI, G.A. et al. Milho crioulo: tecnologia viável e sustentável. Agroecologia e Desenvolvimento Rural Sustentável, v.3, n.1, p.12-17, 2002

MILLER, J.D. Fungi and Mycotoxins in grain: implications for stored product research. Journal Stored Products Research, v.31, n.1, p.1-16, 1995. Disponível em: <http://www.sciencedirect. com/science/article/pii/0022474X9400039V $>$. Acesso em: 15 ago. 2011. doi: 10.1016/0022-474X(94)00039-V.

NEVES, I.P. Armazenamento de grãos. Rede de tecnologia da Bahia - RETEC-BA, 2007. p.1-20. (Dossiê Técnico, 25 julho). Disponível em: <http://www.sbrt.ibict.br/dossietecnicodownloadsDT/MTM5>. Acesso em: 20 jun. 2011.

OLIVEIRA, J.A. et al. Comportamento de sementes de milho tratadas com fungicidas antes e após o armazenamento convencional. Revista Brasileira de Sementes, v.19, n.2 p.208$213,1997$.

PATERNIANI, E. et al. O valor dos recursos genéticos de milho para o Brasil: uma abordagem histórica da utilização do germoplasma. In: UDRY, C.W.; DUARTE, W. (Org.). Uma história brasileira do milho: o valor dos recursos genéticos. Brasília: Paralelo 15, 2000. p.11-41.

PINTO, N.F.J.A. Tratamento fungicida de sementes de milho contra fungos do solo e o controle de Fusarium associado às sementes. Scientia Agricola, v.57, n.3, p.483-486, 2000
Disponível em: <http://www.scielo.br/scielo.php?script=sci_artte xt\&pid=S0103-90162000000300017>. Acesso em: 15 ago. 2011. doi: $10.1590 / \mathrm{S} 0103-90162000000300017$.

POPINIGIS, F. Fisiologia da semente. 2.ed. Brasília: PAX, 1985. 289 p.

SARTORI, A.F et al. Quantificação da transmissão de Fusarium moniliforme de sementes para plântulas de milho. Fitopatologia Brasileira, v.29, n.4, p.456-458, 2004. Disponíve em: $\quad<$ http://www.scielo.br/scielo.php?script=sci_arttext\&pid =S0100-41582004000400018>. Acesso em: 11 ago. 2011. doi: $10.1590 / \mathrm{S} 0100-41582004000400018$

SILVA, S.D.A. et al. Guia para produção de sementes de milho variedade na propriedade de base familiar. Pelotas: EMBRAPA-CNPCT, 2005. 30p. (Documentos, 146).

SOLORZANO, C.D.; MALVICK, D.K. Effects of fungicide seed treatments on germination, population, and yield of maize grown from seed infected with fungal pathogens. Field Crops Research, v.122, p.173-178, 2011. Disponível em: <http://www. sciencedirect.com/science/article/pii/S0378429011000608>. Acesso em: 15 ago. 2011. doi: 10.1016/j.fcr.2011.02.011.

TANAKA, M.A.S. Sobrevivência de Fusarium moniliforme em sementes de milho mantidas em duas condições de armazenamento. Fitopatologia Brasileira, v.26, n.1, p.60-64, 2001. Disponível em: $<$ http://www.scielo.br/scielo.php? script $=$ sci_arttext\&pid $=S 0100$ 41582001000100010\&lng=en\&nrm $=$ iso\&tlng $=\mathrm{pt}>$. Acesso em: 15 ago. 2011. doi: 10.1590/S0100-41582001000100010.

VENTURA, J.A. Taxonomia de Fusarium e seus segredos. Parte II - Chaves para identificação. Revisão Anual de Patologia de Plantas, v.8, p. 303-338, 2000.

WAGNER, M.M.; MITSCHUNAS, N. Fungal effects on seed bank persistence and potential applications in weed biocontrol: a review. Basic and Applied Ecology, v.9, p.191-203, 2008. Disponível em: <http://www.sciencedirect.com/science/article/pii/ S1439179107000175>. Acesso em: 15 ago. 2011. doi: 10.1016/j. baae.2007.02.003.

WEINBERG, Z.G. et al. The effect of moisture level on highmoisture maize (Zea mays L.) under hermetic storage conditionsin vitro studies. Journal of Stored Products Research, v.44, p.136-144, 2008. Disponível em: <http:/www.sciencedirect.com/ science/article/pii/S0022474X07000902>. Acesso em: 15 ago. 2011. doi: 10.1016/j.jspr.2007.08.006

WICKLOW, D.T. et al. Fungal colonists of maize grain conditioned at constant temperatures and humidities. Jounal Stored Products Research, v.34, n.4, p.355-361, 1998. Disponível em: <http://ddr. nal.usda.gov/dspace/handle/10113/13247>. Acesso em: 15 ago. 2011. 